\title{
Extended exposure to elevated temperature affects escape response behaviour in coral reef fishes
}

\author{
Donald T Warren Corresp., 1, 2 ， Jennifer M Donelson ${ }^{2,3}$ ， Mark I McCormick ${ }^{1,2}$ \\ 1 Department of Marine Biology and Aquaculture, James Cook University of North Queensland, Townsville, Queensland, Australia \\ 2 Centre of Excellence for Coral Reef Studies, ARC Centre of Excellence for Coral Reef Studies, Townsville, Queensland, Australia \\ 3 School of Life Sciences, University of Technology Sydney, Sydney, New South Wales, Australia \\ Corresponding Author: Donald T Warren \\ Email address: donald.warren@my.jcu.edu.au
}

The threat of predation, and the prey's response, are important drivers of community dynamics. Yet, environmental temperature can have a significant effect on predation avoidance techniques such as fast-start performance observed in marine fishes. While it is known that temperature increases can influence performance and behaviour in the shortterm, little is known about how species respond to extended exposure during development. We produced a startling response in two species of damselfish, the lemon damsel Pomacentrus moluccensis, and the Ambon damselfish Pomacentrus amboinensis, by the repeated use of a drop stimulus. We show that the length of thermal exposure of juveniles to elevated temperature significantly affects this escape responses. Short-term (4d) exposure to warmer temperature affected directionality and responsiveness for both species. After long-term (90d) exposure, only P. moluccensis showed beneficial plasticity, with directionality returning to control levels. Responsiveness also decreased in both species, possibly to compensate for higher temperatures. There was no effect of temperature or length of exposure on latency to react, maximum swimming speed, or escape distance suggesting that the physical ability to escape was maintained. Evidence suggests that elevated temperature may impact some fish species through its effect on the behavioural responses while under threat rather than having a direct influence on their physical ability to perform an effective escape response. 
1 EXTENDED EXPOSURE TO ELEVATED TEMPERATURE AFFECTS

2 ESCAPE RESPONSE BEHAVIOUR IN CORAL REEF FISHES

3 Donald T. Warren ${ }^{1,2 *}$, Jennifer M. Donelson ${ }^{2,3}$ and Mark I. McCormick ${ }^{1,2}$

$4{ }^{1}$ Department of Marine Biology and Aquaculture, College of Science and Engineering, James

5 Cook University, Townsville, Queensland, 4811 Australia

$6{ }^{2} \mathrm{ARC}$ Centre of Excellence for Coral Reef Studies, James Cook University, Townsville,

7 Queensland, 4811 Australia

$8{ }^{3}$ School of Life Sciences, University of Technology Sydney, PO Box 123, Broadway, New South

9 Wales, 2007 Australia

$10 *$ Author of correspondence:

11 Donald T. Warren

12 Email: donald.warren@my.jcu.edu.au

13 Journal: PeerJ 


\section{Abstract}

15 The threat of predation, and the prey's response, are important drivers of community dynamics.

16 Yet, environmental temperature can have a significant effect on predation avoidance techniques

17 such as fast-start performance observed in marine fishes. While it is known that temperature

18 increases can influence performance and behaviour in the short-term, little is known about how

19 species respond to extended exposure during development. We produced a startling response in two species of damselfish, the lemon damsel Pomacentrus moluccensis, and the Ambon

21 damselfish Pomacentrus amboinensis, by the repeated use of a drop stimulus. We show that the

22 length of thermal exposure of juveniles to elevated temperature significantly affects this escape

23 responses. Short-term (4d) exposure to warmer temperature affected directionality and

24 responsiveness for both species. After long-term (90d) exposure, only P. moluccensis showed

25 beneficial plasticity, with directionality returning to control levels. Responsiveness also decreased

26 in both species, possibly to compensate for higher temperatures. There was no effect of

27 temperature or length of exposure on latency to react, maximum swimming speed, or escape

28 distance suggesting that the physical ability to escape was maintained. Evidence suggests that

29 elevated temperature may impact some fish species through its effect on the behavioural responses

30 while under threat rather than having a direct influence on their physical ability to perform an

31 effective escape response. 
33

34

35

36

37

38

39

40

41

42

43

44

\section{INTRODUCTION}

Predator-prey interactions are one of the key drivers structuring communities (Lima \& Dill, 1990).

Predation pressure can alter prey morphology, regulate population size, and control biodiversity (Sih et al., 1985). Similarly, antipredator responses of prey reduce the efficacy of predators and enhance survival. Factors that influence predator attack success or prey escape performance may alter the outcome of these interactions, potentially causing a cascade of trophic effects. Increased temperature has already been shown to affect antipredator responses in terrestrial ectotherms (Cury de Barros et al., 2010), freshwater fishes (Weetman, Atkinson \& Chubb, 1998), and marine species (Allan et al., 2015). Understanding how changes in environmental temperature can affect key ecological processes can be useful when predicting the composition of future communities.

Rising environmental temperatures can substantially impact the behaviour and locomotor performance components of escape responses in fish (Domenici, 2010). Previous studies have shown that temperature can influence locomotor performance through physiological mechanisms like muscle performance (Johnston, Fleming \& Crockford, 1990) and enzyme activity (Johnson \& Bennett, 1995). Additionally, temperature can affect behavioural components of escape responses, including responsiveness (Preuss \& Faber, 2003) and directionality (Szabo et al., 2008). The effect of environmental temperature will depend on both the level of thermal change compared to the normal thermal conditions, and the length of time thermal change is experienced (Munday, McCormick \& Nilsson, 2012). With sufficient exposure time, plasticity can occur resulting in changes to the phenotype, which potentially reduce the negative impacts of rising temperature (Angilletta, 2009). Exposure during the early stages of life is believed to unlock greater plasticity in traits (West-Eberhard, 2003), and this has been found to be true for coral reef fishes (Donelson et al., 2011). While many studies have investigated the effects of short-term exposure to elevated 
56 temperatures in adult fishes, to date few studies have examined how juvenile fishes respond to

57 long-term exposure to near-future temperature increases.

58

The interaction between a predator and its prey is an intricate sequence that, at its end, leads to a predator striking at a prey and the prey being captured or escaping (Lima \& Dill, 1990). Many amphibians and fishes undertake a C-start escape response to a startling stimulus (Bullock, 1984) involving a sudden acceleration away from the direction of the perceived threat (Domenici \& Blake, 1997). C-start responses are controlled by two large neurons called Mauthner cells, one for each lateral half of the body (Eaton, Bombardieri \& Meyer, 1977). When a stimulus is detected, the corresponding Mauthner cell triggers the escape response resulting in a rapid contraction of white muscle fibres. At first, the fish bends into a C-shape (stage 1), then contralateral contraction releases this tension which propels the fish to flee the stimulus in the opposite direction (stage 2) (Eaton, Bombardieri \& Meyer, 1977). The initiation of C-starts are neurally controlled with maximum performance believed to be limited by muscle power output (Wakeling \& Johnston, 1998). However, fish rarely perform at their maximal limits (Webb, 1986) and modulation of performance during an escape response has been shown to occur in different behavioural contexts, showing there is potential for optimisation (Korn \& Faber, 2005; Domenici, 2010; Ramasamy, Allan \& McCormick, 2015). This supports the economic model that individuals balance the energetic cost of escaping with the threat of predation (Ydenberc \& Dill, 1986). How long-term exposure to elevated temperature can alter behavioural components of an escape response is still unknown.

The present study examines whether short-term or long-term exposure to elevated temperature regimes affect the fast-start escape response in two tropical damselfishes. Using a repeatable drop stimulus (i.e. a stimulus that was consistently replicated), we compared escape 
responses of juveniles from current-day controls $\left(29^{\circ} \mathrm{C}\right)$ to individuals exposed to 50 and 100 year projections (30 and $31{ }^{\circ} \mathrm{C}$; Collins et al. 2013) for either $4 \mathrm{~d}$ or $90 \mathrm{~d}$. Specifically, we tested: (1) the effects of short-term exposure to elevated temperature as an indication of thermal sensitivity and (2) how short-term exposure differed to long-term exposure at elevated temperature as an indication of plasticity. The inclusion of two species was to explore the species-specific effect that temperature had on escape responses.

\section{METHODS}

\section{Ethics statement and collecting permits}

All work reported herein was conducted under permits from James Cook University Animal Ethics Committee (A2079), the Great Barrier Reef Marine Park Authority (G10/33239.1), and Queensland Fisheries (170251).

\section{Study species, collection, and holding facilities}

To examine how short-term and long-term exposure to elevated temperatures influences escape performance, two reef fish species were used (the Lemon damselfish, Pomacentrus moluccensis, and the Ambon damselfish, Pomacentrus amboinensis). These species have been used in past studies on escape performance (Allan et al., 2013) and behaviour (McCormick \& Weaver, 2012) making them familiar study species. These species co-occur across the Indo-Pacific from the southern Great Barrier Reef up to Indonesia and Japan (Allen, 1991). Like many reef fish, these species undergo embryonic development during a pelagic larval phase. After 3-4 weeks, larvae make their final metamorphosis and recruit back to the reef to join the adult population. Both species settle to the reef at similar ages, though standard length of $P$. amboinensis, tends to be slightly larger (McCormick \& Weaver, 2012). Here, thermal plasticity is ecologically important 
101 as individuals often settle to reefs with thermal regimes different to what they experienced as 102 larvae. Recently settled recruits (aged 1-2 months) were collected from the Cairns region ($10316^{\circ} 78^{\prime} \mathrm{S}, 146^{\circ} 26^{\prime} \mathrm{E}$ ) of the Great Barrier Reef, Australia in January 2014. At this latitude, these 104 species do not mature for at least one year, making our individuals immature juveniles. Therefore, 105 gender was not observed as it is not relevant at this age. Once mature, individuals will sex-change 106 depending on social structure (Fishelson, 1998).

Fish were transported back to a closed system holding facilities at the Marine and

108

109

110

111

112

113

114

115

116

117

118

119

120

121

122 123
Aquaculture Research Facilities Unit (MARFU), James Cook University, Townsville. Fish were housed in densities of three of varying sizes (e.g. one big, medium, and small) in 40 litre replicate tanks. This sizing order helped formed a natural hierarchy within tanks and reduced within tank fighting. Tanks were randomly allocated into one of three temperatures: $29.0{ }^{\circ} \mathrm{C}$ (current-day summer average for the collection region; control; AIMS 2014), $30.0^{\circ} \mathrm{C}$, or $31.0^{\circ} \mathrm{C}$ (projected 50 and 100 year future temperatures; Collins et al. 2013). Holding tank temperatures were computer monitored via Innotech Genesis II controller V5 temperature system capable of controlling random fluctuation less than $0.1{ }^{\circ} \mathrm{C}$ for the system. The system was continuously supervised by the inhouse staff at the facility and automatically notified of any irregularities. To avoid thermal stress, the temperature was raised $1{ }^{\circ} \mathrm{C}$ per day (Gardiner, Munday \& Nilsson, 2010; Nilsson, ÖstlundNilsson \& Munday, 2010). Elevated temperatures were split into two exposure lengths: 4d or 90d. A 90d period was chosen for our long-term exposure treatment based on previous developmental studies on this species (Grenchik, Donelson \& Munday, 2013) and a closely related species of damselfish (Donelson et al., 2011). A 4d period was chosen for our short-term exposure treatment to observe the effects of increased temperature without causing a thermal stress response (Gardiner, Munday \& Nilsson, 2010). No thermal benefit in plasticity has been shown to occur in 
$124 P$. moluccensis for up to 22 days of exposure to similar elevated temperatures supporting our $4 \mathrm{~d}$

125 treatment would not be confounded by reversible plasticity (Nilsson, Östlund-Nilsson \& Munday,

126 2010). Temperature variation and photoperiod followed natural diurnal cycle for the collection

127 region, $\pm 0.6{ }^{\circ} \mathrm{C}$ around the mean and $12: 12 \mathrm{~h}$ respectively (AIMS, 2014). Food quantity was not

128 controlled for and all fish were given a high performance commercial fish pellet (NRD 0.5-0.8

$129 \mathrm{~mm}$; Primo aquaculture, QLD, Australia) once or twice daily to satiation. Excess food was

130 removed and tanks were cleaned via a vacuum siphon weekly or as needed.

131 Experimental design

132 The escape performance of fishes was quantified using a repeatable drop stimulus (i.e. a stimulus

133 with mechanical release that could be replicated consistently). Thermal sensitivity to elevated

134 temperature (aim 1) was measured by exposing individuals to either 30 or $31^{\circ} \mathrm{C}$ for a $4 \mathrm{~d}$ period.

135 To explore the extent of thermal plasticity (aim 2), separate treatments were held at either 30 or 31

$136{ }^{\circ} \mathrm{C}$ for $90 \mathrm{~d}$. The control treatment remained at $29^{\circ} \mathrm{C}$ for the entirety of the experiment. In total,

137 there were 10 treatments: 2 short-term exposures, 2 long-term, 1 control, and repeated for each

138 species. Holding tank temperatures were raised $1{ }^{\circ} \mathrm{C} /$ day to reduce the effect of heat shock

139 (Gardiner, Munday \& Nilsson, 2010). To control for any effect of time spent in captivity, the 4d

140 treatments were first held at control temperature, then exposed to their randomly assigned

141 temperature 4 days before the end of the long-term duration. This allowed all fish to finish

142 temperature treatments at the same time.

\section{Experimental procedure}

144 After the exposure period, individuals were measured (standard length, $\bar{x} \pm \mathrm{SD}$; P. amboinensis $\mathrm{n}$ $145=58,30.57 \pm 5.79 \mathrm{~mm}$, P. moluccensis $\mathrm{n}=83,28.08 \pm 3.59 \mathrm{~mm}$ ) and tested for escape performance 
146 the following day. Treatments of $P$. amboinensis were significantly larger than $P$. moluccensis $(F-$

$1471,131=9.52, p=0.002)$, however there were no differences across treatments for each species.

148 Escape performance was tested in a circular arena $(30 \mathrm{~cm}$ diameter $)$ filled to a depth of $10 \mathrm{~cm}$ to

149 reduce movement in the vertical plane and illuminated with fluorescent lighting strips. Water

150 temperature of the arena reflected the treatment temperature that fish were held in. Water

151 temperature was monitored with a C20 Comark thermometer (Comark corp., Norfolk, UK).

152 Temperature was maintained with a glass bar heater (Aqua One, 300W) and air stone for aeration.

153 Complete water exchanges were conducted every 10 minutes or after 3 fish. The walls and top had

154 opaque covers to prevent outside disturbance. To elicit an escape response, a startling stimulus

155 consisting of a weight with a tapered end was released through a tube suspended above the centre

156 of the arena. The suspended tube stopped $\sim 1 \mathrm{~cm}$ above the water's surface concealing the stimulus

157 weight as it fell thus creating a more sudden disturbance. A monofilament line was used to raise

158 the weight and was long enough that the end touched just the water's surface when released,

159 preventing collision with the individual. To start a trial, fish were placed into a central habituation

160 ring (10 cm diameter) via a water filled sample jar and given a one-minute habituation period.

161 Following the habituation period, the central ring was gently raised and the stimulus weight was

162 released, striking the water in an attempt to elicit an escape response. If a C-start was performed,

163 no further attempts were conducted and the fish was returned to its holding tank. If no reaction

164 was observed, fish were replaced into the habituation ring for another minute and the second

165 attempt was conducted. Fish were given three attempts to perform a C-start before being recorded

166 as "no reaction". The escape response was recorded using a high-speed camera (Casio Exilim Ex-

$167 \mathrm{~F} 1 ; 600 \mathrm{fps}$ ) directed at a $45^{\circ}$ angled mirror placed beneath the testing tank. 
169 Response variables were measured using the fish's centre of mass ( $\sim 35 \%$ SL from the snout; Webb

170 1976) and tracked using ImageJ software (v1.48) with the manual tracking plugin. We chose our

171 variables as they have been used in previous study as a good indicator of escape ability (Walker et

172 al., 2005). Only stages 1 and 2 of the C-start, described as directional changes in the anterior part

173 of the body (Domenici \& Blake, 1997) were quantified.

174 Non-locomotor

175 a) Responsiveness: proportions of fish that responded with a "C-start" or "no C-start". No C-

176 start was subdivided into "avoid" to the stimulus by swimming away but not performing a

177 desired C-start and "no reaction" to the stimulus.

178 b) Directionality: left and right side were split anteroposteriorly from directly above the fish.

179 Directionality was determined by whether the head turned "away" or "toward" the side the 180 stimulus occurred during stage 1 of the response.

181 c) Response latency (ms): time between the stimulus onset and first movement of the individual.

Locomotor

183

d) Escape distance $(\mathrm{mm})$ : distance travelled during the response to the end of stage 2 .

184

e) Maximum swim speed (body lengths $\mathrm{s}^{-1}$ ): maximum velocity achieved at any time during the escape response.

186

187

188

189

190

Data analysis

Statistical analyses were performed using IBM SPSS statistics (v23.0.0.2). Proximity of fish to the stimulus at the onset and body size can affect escape responses (Webb, 1976). The central habituation ring helped reduce differences in starting proximity to stimulus and the remaining distances of fish to the stimulus did not differ among treatments (one-way ANOVA $F_{4,110}=0.959$, 
$191 P=0.433)$. Maximum swim speed $\left(\mathrm{m} \mathrm{s}^{-1}\right)$ was converted to body length $\mathrm{s}^{-1}$ to control for any effect

192 of size. Control temperature did not consist of two exposure combinations like the elevated

193 temperatures, therefore a full-factorial 3x2 design was not possible. Instead, the five treatments

194 (control, 2 short-term, and 2 long-term) were categorised into one "temperature treatment" factor.

195 A binomial logistic regression was used to ascertain the effects of temperature treatment on the

196 likelihood of an individual to elicit a C-start after the stimulus and the likelihood of that individual

197 to turn away from the stimulus. Response latency, maximum swim speed, and escape distance

198 were used as dependent variables analysed separately with one-way ANOVAs $(\alpha=0.05)$ and 199 temperature treatment as the fixed factor. These analyses were repeated for both species (replicates

200 ranged from 7-12 for $P$. amboinensis and 9-19 for P. moluccensis). Preliminary analysis of

201 response latency, maximum swim speed, and response distance used a linear mixed effects model

202 with holding tank as a random factor to test for a tank effect. However, AIC values were lower for

203 models not including random tank factor with $\Delta \mathrm{AIC}<2$ to models that did include random tank

204 factor. Consequently, this term was dropped from the final model. We predicted that short-term

205 exposure to elevated temperature would have a negative impact on escape responses. If beneficial

206 plasticity was possible with long-term exposure, individuals exposed for 90d would exhibit

207 improvement in performance that either approached or returned to present-day control levels.

\section{RESULTS}

209 There was no significance in the logistic regression model for responsiveness in $P$. amboinensis $210\left(\chi^{2}(4)=4.18, p=0.38 ;\right.$ Fig $\left.1 a\right)$. At control, 84.62\% of individuals responded with a C-start, 7.69\%

211 showed no reaction, and 7.69\% displayed avoidance behaviour. Exposure of 4 days to either 30 or

$21231{ }^{\circ} \mathrm{C}$ had very little effect on responsiveness. However, for individuals that did not display a C-

213 start, all showed no reaction to the stimulus and none displayed avoidance behaviour. After 90 
214 days, fish were 2.19 times less likely (71.43\%) to perform a C-start at $30{ }^{\circ} \mathrm{C}$ and 3.14 times less

215 likely $(63.64 \%)$ at $31{ }^{\circ} \mathrm{C}$. Additionally, avoidance behaviour was returned (14.29\%) and divided

216 non C-start individuals in half with those showing no reaction (14.29\%). There was significance

217 in the regression model for directionality in P. amboinensis $\left(\chi^{2}(4)=11.23, p=0.024\right.$; Fig $\left.1 b\right)$.

218 The model explained $28.70 \%\left(\right.$ Nagelkerke $\mathrm{R}^{2}$ ) of the variance in directionality of C-starts and

219 correctly classified $67.60 \%$ of cases. Compared to controls, fish exposed to $30{ }^{\circ} \mathrm{C}$ for 4 days were

2205 times more likely (33.33\%) to turn towards the stimulus and 6.67 times more likely (40\%) after

22190 days. At $31^{\circ} \mathrm{C}$, fish were 25 times more likely $(71.43 \%)$ to turn towards the stimulus, which

222 was the same for both exposure durations. Temperature nor exposure duration had any significant

223 effect on response latency $\left(F_{4,42}=1.32, p=0.27\right.$, partial $\eta^{2}=0.053$; Fig $\left.2 a\right)$, maximum swim speed

$224\left(F_{4,41}=0.6, p=0.66\right.$ partial $\eta^{2}=0.056 ;$ Fig $\left.2 b\right)$, or response distance $\left(F_{4,42}=0.65, p=0.62\right.$, partial

$225 \eta^{2}=0.058 ;$ Fig $2 c$ ) for P. amboinensis.

226 For P. moluccensis, logistic regression model for responsiveness was statistically significant $\left(\chi^{2}\right.$

$227(4)=16.58, p=0.002$; Fig $1 a)$. The model explained 28\% (Nagelkerke $\mathrm{R}^{2}$ ) of the variance in

228 proportion of individuals that elicited a C-start and correctly classified $80 \%$ of cases. At control,

$22982.61 \%$ of fish displayed a C-start. Of the fish that did not C-start, most showed avoidance

230 behaviour (13.04\%) and no reaction (4.35\%) least of all. Responsiveness rose to absolute (i.e.

$231100 \%$ of individuals performed a C-start) after 4 days of exposure to either 30 or $31{ }^{\circ} \mathrm{C}$. When 90

232 day exposure was compared to controls, individuals were 1.45 times less likely (76.47\%) to

233 perform a C-start at $30{ }^{\circ} \mathrm{C}$ and 3.55 times less likely $(57.14 \%)$ at $31{ }^{\circ} \mathrm{C}$. For individuals that did

234 not display a C-start, there was an increase in no reaction up to $38 \%$ at $31{ }^{\circ} \mathrm{C}$ (from $4.35 \%$ at

235 control). There was no significance in the regression model for directionality $\left(\chi^{2}(4)=5.98, p=\right.$

2360.20 ; Fig $1 b)$. Fish with 4 days of exposure to $30{ }^{\circ} \mathrm{C}$ were 2.8 times more likely $(50 \%)$ to turn 
237 towards the stimulus compared to controls and 4.2 time more likely $(60 \%)$ at $31^{\circ} \mathrm{C}$. However, this

238 was reduced after prolonged exposure where directionality was very similar to control (23.08\%

239 and $25 \%$ for 30 and $31^{\circ} \mathrm{C}$, respectively). There was no significant effect of temperature and

240 exposure duration on response latency $\left(F_{4,60}=1.23, p=0.30\right.$, partial $\eta^{2}=0.052$; Fig $\left.2 a\right)$, maximum

241 swim speed $\left(F_{4,60}=0.19, p=0.94\right.$, partial $\eta^{2}=0.013 ;$ Fig $\left.2 b\right)$, nor response distance $\left(F_{4,60}=0.85\right.$,

$242 p=0.49$, partial $\eta^{2}=0.054$; Fig $2 c$ ) for P. moluccensis.

\section{DISCUSSION}

244 Studying how escape responses are affected by elevated temperature can be important when making predictions on the ability of prey to escape predators under climate change conditions

246 (Gilman et al., 2010). Supporting our predictions, we found short-term exposure to elevated

247 temperature negatively impacted directionality for both species. However, there was little effect

248 on responsiveness, response latency, maximum, swim speed, and escape distance. After long-term

249 exposure, directionality in P. moluccensis followed our predictions by reducing the number of

250 turns towards the stimulus and returning to control levels. For P. moluccensis, long-term exposure

251 also altered responsiveness with fish responding less often with a C-start response at elevated

252 temperatures. Such alterations in the C-start responsiveness to predators is likely to change prey

253 survival, while the differential effects of temperature on the two closely related species suggests

254 that future temperature elevation may affect community composition through differential survival.

The ability for prey to perceive and avoid a predatory threat is essential to survival.

Directionality in escape responses is important as turning towards a stimulus would increase exposure time to a predator (Domenici, 2010). Short-term exposure to elevated water temperature study on goldfish also found directionality was impaired at increased temperatures compared to 
260 controls (Szabo et al., 2008). Altered directionality may have been due to an impairment of

261 sensorimotor control (Foreman \& Eaton, 1993). While not significant, short-term exposure to

262 elevated temperatures increased C-start responsiveness in P. moluccensis from $80 \%$ to $100 \%$, and

263 reduced avoidance reactions to $0 \%$ for both species. Generally, proportion of C-starts has been

264 shown to increase with exposure to temperature both above (Szabo et al., 2008) and below control

265 treatments (Preuss \& Faber, 2003), suggesting responsiveness may increase with thermal stress, at

266 either extreme. Hyperactivity under stress can be beneficial to survival, as a fish that does not react

267 during a predator attack will most likely get eaten. However, this strategy can risk expending

268 additional energy on a false or non-threatening stimulus.

269 Extended exposure to new environmental conditions can alter the physiological and 270 behavioural response of individuals (Angilletta, 2009). We found directionality in P. moluccensis

271 showed signs of beneficial plasticity after long-term exposure by returning to control levels. Long-

272 term exposure may have reduced the negative impact of sensorimotor control brought on by

273 thermal stress. Physiological plasticity to similar temperatures $\left(+2{ }^{\circ} \mathrm{C}\right)$ in this species has also been

274 shown to occur for aerobic metabolism (Grenchik, Donelson \& Munday, 2013) potentially

275 demonstrating that $P$. moluccensis could exhibit beneficial plasticity to future projected

276 temperatures in a range of traits. The proportion of C-starts reduced while avoidance behaviour

277 increased with long-term exposure in both species. Decreasing the proportion of C-starts deviates

278 further from control levels, therefore cannot be considered beneficial. However, future sea

279 temperature increases are expected to exceed the thermal optimum for many reef fish (Tewksbury,

280 Huey \& Deutsch, 2008). forcing species to adopt energy saving strategies (Ydenberc \& Dill, 1986).

281 Reducing the proportion of C-starts and replacing with avoidance behaviour may help compensate

282 for the costs of increasing thermal conditions. 
While other studies have shown that elevated temperature affects the locomotor

284

performance in fast-starts (Webb \& Zhang, 1994; Beddow, Leeuwen \& Johnston, 1995), we found projected increased sea temperatures had no effect on maximum swim speed or escape distances in our species, regardless of exposure duration. Similarly, we found no effect on response latency with temperature and exposure duration. The lack of change in performance at these temperatures indicates once a C-start was initiated, the physical ability to escape is maintained. This suggests future warming may have little effect on mortality rates. Although promising, this may be problematic because metabolic demands for fish increase with rising ambient temperature (Nilsson, Östlund-Nilsson \& Munday, 2010; Grenchik, Donelson \& Munday, 2013) and C-starts are high energy manoeuvres (Jayne \& Lauder, 1993). If an individual's energy budget is limited, then more resources must be allocated to the rising cost of metabolic demands and potentially leave less available for other activities such as escape behaviour (Careau et al., 2008). Thus, the behavioural modulation of reducing C-start responsiveness after long-term exposure observed, may act as a means of balancing the increasing cost of C-starts at higher temperature.

To conclude, both species showed negative effects of increased temperature after shortterm, though the impact was greater for P. amboinensis. After long-term exposure, P. moluccensis adjusted to temperature with beneficial plasticity and energy saving strategies. These results show the C-start escape response possesses thermal plasticity and extended exposure can induce beneficial changes. The difference in response by species matches a previous study showing $P$. moluccensis possessed a higher capacity for thermal plasticity in aggressive interactions (Warren et al., 2016). Changes in escape behaviour will ultimately affect mortality rates in prey and the species-specific response suggests some will better cope with future temperatures. This study is important as it illustrates the specific contribution that elevated temperature will have on individual 
306 performance. However, comprehensive climate change scenarios will also include responses to

307 changes in ocean chemistry $\left(\mathrm{CO}_{2}\right.$ levels and $\left.\mathrm{pH}\right)$. Furthermore, precise measurement of escape

308 success will require future study with only the prey, only the predator, and both exposed to elevated

309 temperature as predators will also likely have specific responses to thermal conditions. Future

310 studies may also consider a longitudinal approach with several populations from differing sites to

311 consider adaptation to local thermal environments. Studies investigating the factors that influence

312 predator-prey interactions, like this one, are crucial because these interactions determine

313 population sizes and replenishment, leading to changes in community structure.

314 Acknowledgements - We thank Dave Stewart of Affordable Charters, captain of the Kalinda, and

315 the dive volunteers for field assistance. We thank the JCU team at MARFU and Shannon

316 McMahon for their help in the construction and maintenance of the holding facilities. We thank

317 Katie Motson and Shannon McMahon for their aid in collecting burst responses videos. 


\section{REFERENCES}

319 AIMS. 2014. Water temperature for Janurary 2014, Arlington and Moores reefs.

320 Allan BJM., Domenici P., McCormick MI., Watson SA., Munday PL. 2013. Elevated CO2

321 Affects Predator-Prey Interactions through Altered Performance. PLoS ONE 8:e58520.

322 DOI: 10.1371/journal.pone.0058520.

323

324

325

326

327

328

Allan BJM., Domenici P., Munday PL., Mccormick MI. 2015. Feeling the heat : the effect of acute temperature changes on predator - prey interactions in coral reef fish. Conservation Physiology 3:1-8. DOI: 10.1093/conphys/cov011.Introduction.

Allen G. 1991. Damselfishes of the World. Mergus Publishers, Melle, Germany.

Angilletta MJ. 2009. Thermal adaptation: a theoretical and emprirical synthesis. Oxford University Press.

Beddow T., Leeuwen J., Johnston I. 1995. Swimming kinematics of fast starts are altered by temperature acclimation in the marine fish Myoxocephalus scorpius. The Journal of experimental biology 198:203-8.

Bullock TH. 1984. Comparative Neuroethology of Startle, Rapid Escape, and Giant FiberMediated Responses. In: Eaton RC ed. Neural Mechanisms of Startle Behavior. Boston, MA: Springer US, 1-13. DOI: 10.1007/978-1-4899-2286-1_1.

Careau V., Thomas D., Humphries MM., Réale D. 2008. Energy Metabolism and Animal Personality Linked references are available on JSTOR for this article : 117:641-653. DOI: 10.1111/j.2008.0030-1299.16513.x.

Collins M., Knutti R., Arblaster J., Dufresne J., Fichefet T., Friedlingstein P. 2013. Long-term 
Climate Change: Projections, Commitments and Irreversibility. In: Stocker T, Qin D, Plattner G, Tognor M, Boschung J, Nauels A, Xia Y, Bev V, Midgley P eds. Climate Change 2013: The Physical Science Basis. Contributing work to the Fifth Assessment Report of the Intergovernmental Panel on Climate Change. Cambridge University Press, Cambridge, United Kingdom and New York, NY, USA,.

Cury de Barros F., Eduardo de Carvalho J., Abe AS., Kohlsdorf T. 2010. Fight versus flight: the interaction of temperature and body size determines antipredator behaviour in tegu lizards. Animal Behaviour 79:83-88. DOI: 10.1016/j.anbehav.2009.10.006.

Domenici P. 2010. Context-dependent variability in the components of fish escape response: Integrating locomotor performance and behavior. Journal of Experimental Zoology Part A: Ecological Genetics and Physiology 313 A:59-79. DOI: 10.1002/jez.580.

Domenici P., Blake RW. 1997. The kinematics and performance of fish fast-start swimming. The Journal of Experimental Biology 200:1165-1178.

Donelson JM., Munday PL., Mccormick MI., Nilsson GE. 2011. Acclimation to predicted ocean warming through developmental plasticity in a tropical reef fish. Global Change Biology 17:1712-1719. DOI: 10.1111/j.1365-2486.2010.02339.x.

Eaton RC., Bombardieri RA., Meyer DL. 1977. The Mauthner-initiated startle response in teleost fish. The Journal of Experimental Biology 66:65-81.

Fishelson L. 1998. Behaviour, socio-ecology and sexuality in damselfishes (Pomacentridae). Italian Journal of Zoology 65:387-398. DOI: 10.1080/11250009809386853.

Foreman RB., Eaton RC. 1993. The Direction Change Concept for Reticulospinal Control of 
361 Gardiner NM., Munday PL., Nilsson GE. 2010. Counter-gradient variation in respiratory 362 performance of coral reef fishes at elevated temperatures. PLoS ONE 5. DOI: 10.1371/journal.pone.0013299.

364

365

366

367

368

369

370

371

372

373

374

375

376

377

378

379

380

Gilman SE., Urban MC., Tewksbury J., Gilchrist GW., Holt RD. 2010. A framework for community interactions under climate change. Trends in Ecology and Evolution 25:325331. DOI: 10.1016/j.tree.2010.03.002.

Grenchik MK., Donelson JM., Munday PL. 2013. Evidence for developmental thermal acclimation in the damselfish, Pomacentrus moluccensis. Coral Reefs 32:85-90. DOI: 10.1007/s00338-012-0949-1.

Jayne BC., Lauder G V. 1993. Red and white muscle activity and kinematics of the escape response of the bluegill sunfish during swimming. Journal of Comparative Physiology A 173:495-508. DOI: 10.1007/BF00193522.

Johnson T., Bennett a. 1995. The thermal acclimation of burst escape performance in fish: an integrated study of molecular and cellular physiology and organismal performance. The Journal of experimental biology 198:2165-75.

Johnston IA., Fleming JD., Crockford T. 1990. Thermal acclimation and muscle contractile properties in cyprinid fish. American Journal of Physiology - Regulatory Integrative and Comparative Physiology 259:231-236.

Korn H., Faber DS. 2005. The Mauthner cell half a century later: A neurobiological model for decision-making? Neuron 47:13-28. DOI: 10.1016/j.neuron.2005.05.019. 
381 Lima SL., Dill LM. 1990. Behavioral decisions made under the risk of predation: a review and 382 prospectus. Canadian Journal of Zoology 68:619-640. DOI: 10.1139/z90-092.

383

384

385

386

387

388

389

390

391

392

393

394

395

396

397

398

399

400

401

McCormick MI., Weaver CJ. 2012. It pays to be pushy: Intracohort interference competition between two reef fishes. PLoS ONE 7. DOI: 10.1371/journal.pone.0042590.

Munday PL., McCormick MI., Nilsson GE. 2012. Impact of global warming and rising CO2 levels on coral reef fishes: what hope for the future? Journal of Experimental Biology 215:3865-3873. DOI: 10.1242/jeb.074765.

Nilsson GE., Östlund-Nilsson S., Munday PL. 2010. Effects of elevated temperature on coral reef fishes: Loss of hypoxia tolerance and inability to acclimate. Comparative Biochemistry and Physiology - A Molecular and Integrative Physiology 156:389-393. DOI: 10.1016/j.cbpa.2010.03.009.

Preuss T., Faber DS. 2003. Central cellular mechanisms underlying temperature-dependent changes in the goldfish startle-escape behavior. The Journal of neuroscience : the official journal of the Society for Neuroscience 23:5617-5626. DOI: 23/13/5617 [pii].

Ramasamy RA., Allan BJM., McCormick MI. 2015. Plasticity of escape responses: Prior predator experience enhances escape performance in a coral reef fish. PLoS ONE 10:1-9. DOI: 10.1371/journal.pone.0132790.

Sih A., Crowley P., Mcpeek M., Petranka J., Strohmeier K. 1985. Predation, competition, and prey communities : A review of field experiments author. Annual Review of Ecology and Systematics 16:269-311.

Szabo TM., Brookings T., Preuss T., Faber DS. 2008. Effects of Temperature Acclimation on a 
402

403

404

405

406

407

408

409

410

411

412

413

414

415

416

417

418

419

420

421

422

Central Neural Circuit and Its Behavioral Output. :2997-3008. DOI:

10.1152/jn.91033.2008.

Tewksbury JJ., Huey RB., Deutsch CA. 2008. Putting the Heat on Tropical Animals. Science 320:1296-1297. DOI: 10.1126/science.1159328.

Wakeling JM., Johnston IA. 1998. Muscle power output limits fast-start performance in fish. The Journal of experimental biology 201:1505-1526.

Walker JA., Ghalambor CK., Griset OL., McKenney D., Reznick DN. 2005. Do faster starts increase the probability of evading predators? Functional Ecology 19:808-815. DOI: 10.1111/j.1365-2435.2005.01033.x.

Warren DT., Donelson JM., McCormick MI., Ferrari MCO., Munday PL. 2016. Duration of Exposure to Elevated Temperature Affects Competitive Interactions in Juvenile Reef Fishes. Plos One 11:e0164505. DOI: 10.1371/journal.pone.0164505.

Webb PW. 1976. The effect of size on the fast-start performance of rainbow trout Salmo cairdneri, and a consideration of piscivorous predator-prey interactions. Journal of experimental biology 65:157-177. DOI: 10.1016/S1546-5098(05)23009-1.

Webb PW. 1986. Effect of Body Form and Response Threshold on the Vulnerability of Four Species of Teleost Prey Attacked by Largemouth Bass (Micropterus salmoides). Canadian Journal of Fisheries and Aquatic Sciences 43:763-771. DOI: 10.1139/f86-094.

Webb PW., Zhang HB. 1994. The Relationship between Responsiveness and Elusiveness of Heat-Shocked Goldfish (Carrassius-Auratus) to Attacks by Rainbow-Trout (OncorhynchusMykiss). Canadian Journal of Zoology-Revue Canadienne De Zoologie 72:423-426. 
423 Weetman D., Atkinson D., Chubb J. 1998. Effects of temperature on anti-predator behaviour in 424 the guppy, Poecilia reticulata. Animal behaviour 55:1361-1372. DOI:

$425 \quad$ 10.1006/anbe.1997.0666.

426 West-Eberhard M. 2003. Developmental plasticity and evolution. Oxford University Press.

427 Ydenberc RC., Dill LM. 1986. The Economics of Fleeing from Predators. 16.

428

429 


\section{Figure 1}

Responsiveness and directionality to the startling stimulus.

C-start responsiveness (a) of fish to a drop stimulus for juvenile Pomacentrus amboinensis (left) and Pomacentrus moluccensis (right) at control, $4 \mathrm{~d}$ or $90 \mathrm{~d}$ exposure durations to elevated temperatures. Types of reaction are: no reaction (grey), avoidance (open), and Cstart (solid). Directionality $(b)$ categorises only C-start individuals by whether first movement of head was towards (solid) or away (open) from the stimulus. 


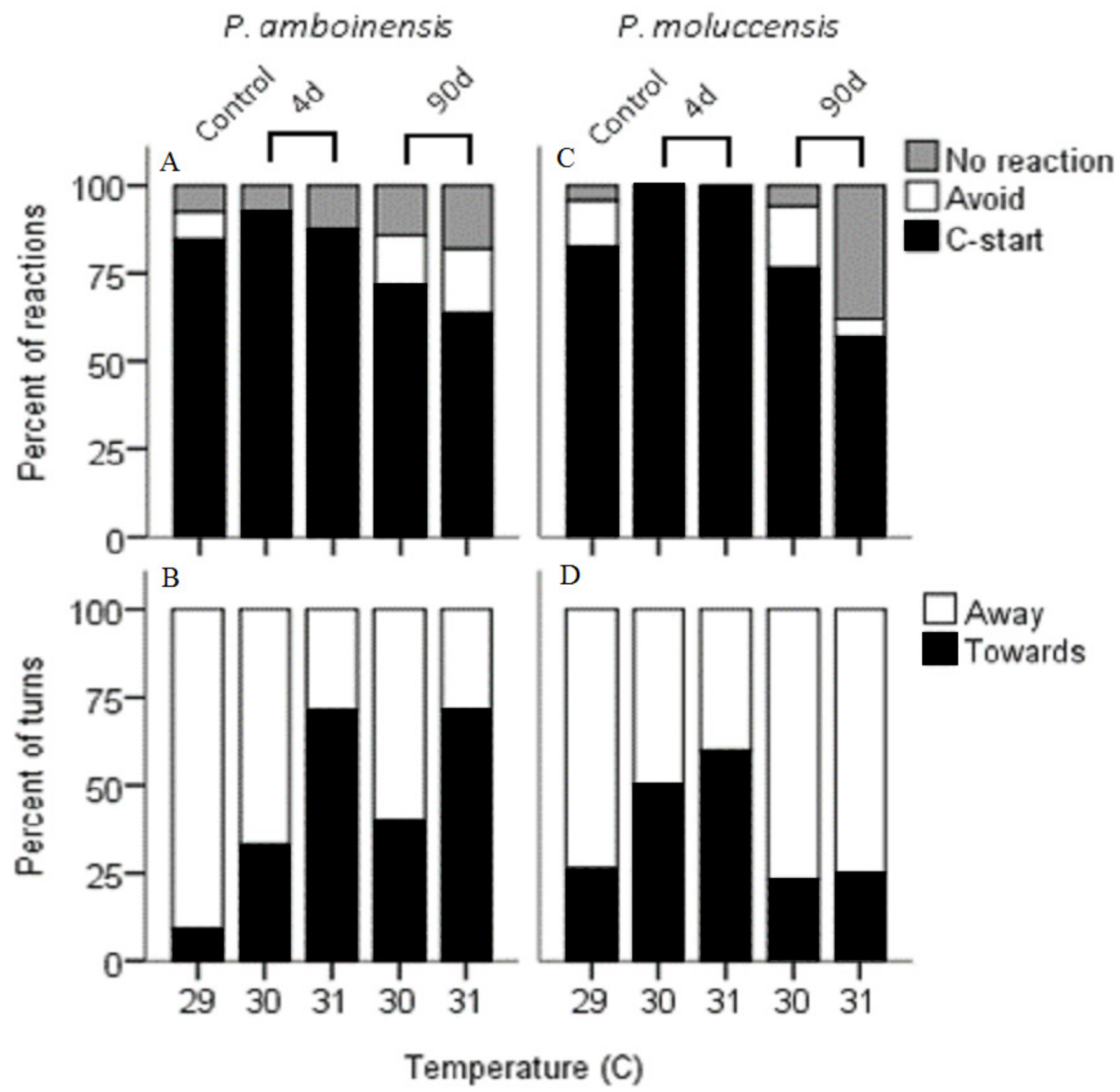




\section{Figure 2}

Measures of kinematic variables to the drop stimulus.

Kinematic performance of fast starts by juvenile $P$. amboinensis (left) and $P$. moluccensis

(right) at control (solid), 4d (open) or 90d (grey) exposure durations to elevated

temperatures. Variables measured were response latency (a), max speed (body lengths $\mathrm{s}^{-1}$;

b), and escape distance (c). 


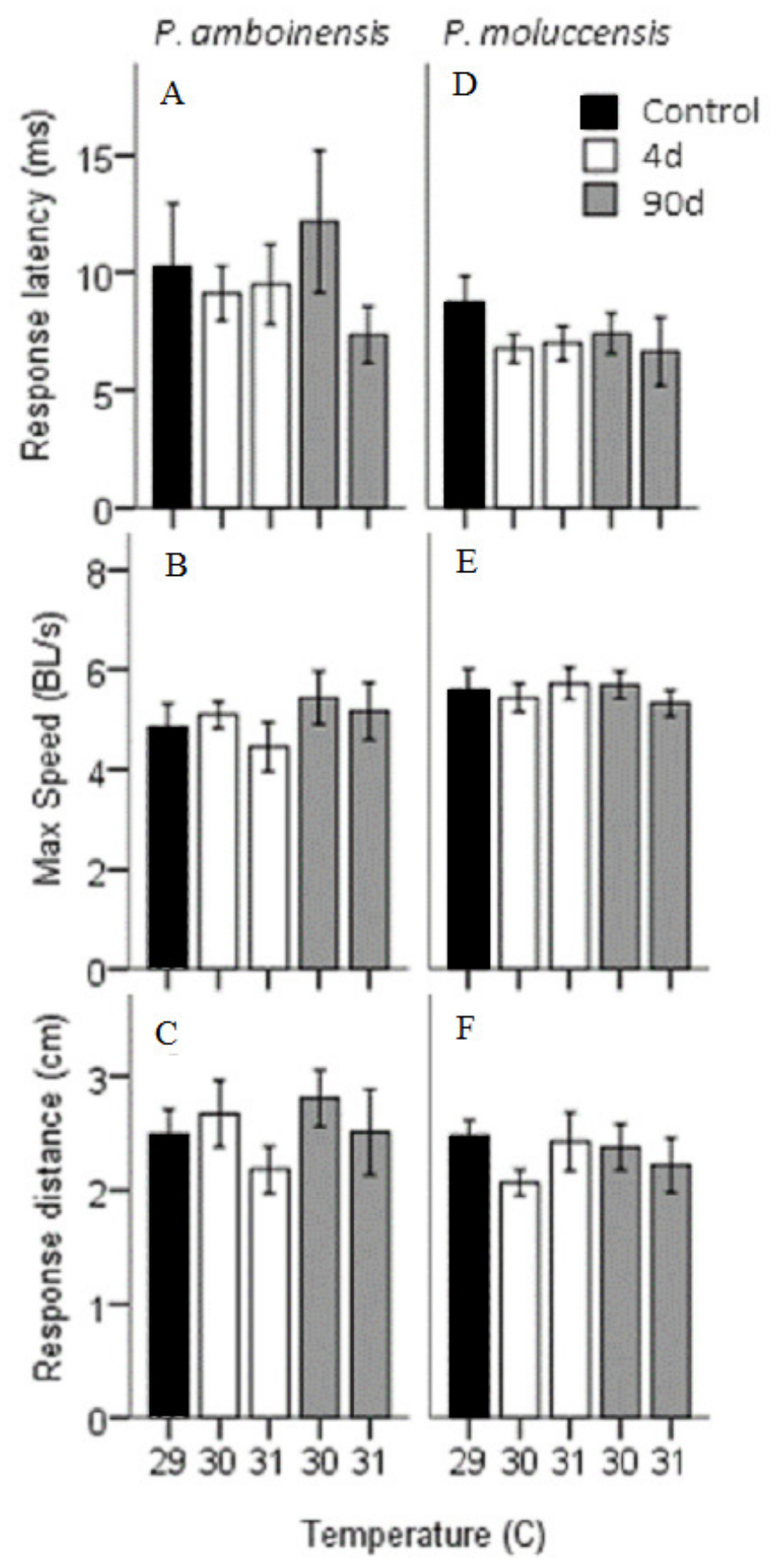

